\title{
Effectiveness of an Underbody Forced Warm-Air Blanket during Coronary Artery Bypass Surgery in the Prevention of Postoperative Hypothermia: A Prospective Controlled Randomized Clinical Trial
}

\author{
J. E. Teodorczyk ${ }^{1,3}$, J. H. Heijmans ${ }^{2 *}$, W. N. K. A. van Mook ${ }^{1}$, D. C. J. J. Bergmans ${ }^{1}$, \\ P. M. H. J. Roekaerts ${ }^{1}$ \\ ${ }^{1}$ Department of Intensive Care, Maastricht University Medical Centre, Maastricht, the Netherlands; ${ }^{2}$ Department of Anesthesiology, \\ Maastricht University Medical Centre, Maastricht, the Netherlands: ${ }^{3}$ Currently working at the Department of Anesthesiology, \\ Academic Medical Center, Amsterdam, the Netherlands \\ Email: $\left\{{ }^{*}\right.$ jh.heijmans, w.van.mook, d.bergmans, p.roekaerts\}@mumc.nl, j.e.teodorczyk@amc.uva.nl
}

Received March $6^{\text {th }}, 2012$; revised April 22 ${ }^{\text {th }}, 2012$; accepted May 20 ${ }^{\text {th }}, 2012$

\begin{abstract}
Introduction: Perioperative hypothermia in cardiac surgery is associated with adverse outcome. The aim of this investigation was to study whether an underbody forced-air warming blanket during coronary artery bypass graft surgery with normothermic cardiopulmonary bypass can prevent postoperative hypothermia. Methods: After Medical Ethics Committee approval, 60 low-risk cardiac surgery patients at random were assigned into a group that received standard thermal care management (control group $\mathrm{n}=30$ ) and a group that received the underbody forced-air warming system plus the standard thermal care (intervention group $\mathrm{n}=30$ ). Results: The temperature after-drop from the end of cardiopulmonary bypass to arrival in the ICU was less in the intervention group versus control group $\left(0.4^{\circ} \mathrm{C} \pm 0.3^{\circ} \mathrm{C}\right.$ vs $0.6^{\circ} \mathrm{C}$ $\pm 0.4^{\circ} \mathrm{C} ; \mathrm{P}=0.027$ ). Out of the intervention group, 27 patients arrived in the ICU with a bladder temperature $\geq 36^{\circ} \mathrm{C}$ $(90 \%)$ as compared to 14 patients $(46.7 \%)$ from the control group $(\mathrm{P}<0.001)$. The peripheral temperature was significantly higher in the intervention group as compared to the control group $(\mathrm{P}<0.001)$. Conclusions: A full underbody forced-air warming blanket prevents postoperative hypothermia in normothermic coronary artery bypass graft surgery patients.
\end{abstract}

Keywords: Cardiac Surgery; Anesthesia; Temperature Monitoring; Peri Operative

\section{Introduction}

Cardiac surgery with near-normothermic cardiopulmonary bypass, remains associated with early postoperative hypothermia due to the drop in core temperature after termination of cardiopulmonary bypass [1].

The combination of anesthesia-induced impairment of thermoregulatory control and the exposure to a cool operating room environment are the main reasons for developing operative and postoperative hypothermia. Although hypothermia reduces basal metabolic rate, thereby potentially decreasing the risk of tissue hypoxia and ischemia [2], numerous studies have shown that perioperative hypothermia is associated with adverse postoperative outcome such as, shivering, coagulopathy with increased transfusion requirement, impaired immune response, wound infection, cardiac morbidity, prolonged drug metabolism and higher costs of care [2-9]. Maintaining pe-

*Corresponding author. rioperative normothermia is therefore important. Covering patients with forced air-warming systems has been reported to be the preferable method to maintain normothermia during prolonged surgery [2].

An underbody forced warm-air blanket was developed in order to prevent postoperative hypothermia. The primary aim of this study, as part of a quality improvement project, was to test the hypothesis that the use of this blanket would lead to a decrease in the occurrence of hypothermia after completion of elective coronary artery bypass graft surgery with normothermic cardiopulmonary bypass.

\section{Materials and Methods}

Within regulations of the Hospitals' Medical Ethics Committee, 60 consecutive patients who underwent elective coronary artery bypass graft surgery were at random assigned to two groups: the intervention group, receiving 
an underbody forced warm-air blanket and standard thermal care $(\mathrm{n}=30)$ and a control group receiving standard thermal care $(\mathrm{n}=30)$.

Exclusion criteria included off-pump coronary artery bypass graft surgery, patients requiring an intra-aortic balloon pump, emergency surgery, a body mass index (BMI) of $\geq 40 \mathrm{Kg} \cdot \mathrm{m}^{-2}$ and fever $\left(\geq 38.5^{\circ} \mathrm{C}\right)$.

Anesthesia management was standardized and consisted of total intravenous anesthesia with propofol and a short-acting opioid. Routine heat conservation methods were applied in both groups and included draping of the patients, use of an infusion fluid warming system (Arizant Irrigation Warming Unit Model 24500) and normothermic heart-lung machine management aiming at $\sim 36.5^{\circ} \mathrm{C}$ with a peripheral-to-core temperature gradient of less than $3^{\circ} \mathrm{C}$. Core temperature was measured with a bladder catheter (Foley catheter, Rüsch Sensor Serie 400 Silicone, Willy Rüsch AG, Kernen, Germany). The operation room temperature was standard at 18 degrees Celcius. The intervention group was additionally treated with an active full underbody forced warm-air system (Bair Hugger full-access underbody blanket Model 635 and Model 750 base unit, Arizant Healthcare, Eden Prairie, MN, USA), which was set at $43^{\circ} \mathrm{C}$ at the end of perfusion until departure from the operating room. Bladder temperature was measured at different time points: $\mathrm{T} 1$ —end of perfusion, T2 - sternal closure, T3-departure from the operating room, T4 - on arrival in ICU.

The use of inotropes, vasoconstrictors and nitrates was not significantly different between groups.

\section{Statistical Analysis}

Baseline variables and surgical data between the two groups were examined for statistical differences using an independent-samples $t$-test. General Linear Model (GLM) with repeated measures was used to investigate the effects of the two different patient-warming techniques. Analyses were performed with group (two groups) as between variable, and time (four (and three) time points for the temperature measurements) as within variable. The individual time points for temperature measurement were tested for significance for between group differences using independent-samples $t$-test. Secondary outcome measures such as temperature after-drop or shivering were tested using an independent-samples $t$-test or Chi-square in case of parametric or nonparametric data respectively. Differences were considered significant at $\mathrm{P}$-values less than 0.05 . All data are presented as mean \pm standard error of the mean. Statistical analyses were performed using SPSS 15.0 for Windows ${ }^{\circledR}$. Sample size was estimated using data from our hospital for CABG surgery patients (temperature upon arrival in the ICU $35.4^{\circ} \mathrm{C} \pm$ $0.7^{\circ} \mathrm{C}$ ) with an expected increase of $1.0^{\circ} \mathrm{C}$ after instal- ment of the warming device [10]. Thirty patients per group would provide $80 \%$ power at the 0.05 significance level to detect a $1{ }^{\circ} \mathrm{C}$ core-temperature difference in the two treatment groups. The estimates for the sample size are similar to those referred to in the literature [11].

\section{Results}

Demographic data were similar in both groups, except for age (Table 1). The mean age in the intervention group was higher than in the control group (70 $\mathrm{yr} \pm 8$ yr vs 65 $\mathrm{yr} \pm 11 \mathrm{yr}, \mathrm{P}=0.032$ ). The number of grafts, perfusion time and cross-clamping time were similar in both groups. The number of patients arriving in ICU with a bladder temperature $\geq 36^{\circ} \mathrm{C}$ was significantly higher in the intervention group than in the control group, 27 patients $(90 \%)$ vs 14 patients $(46.7 \%)$ respectively $(\mathrm{P}<0.001)$ (Figure 1). The effect of additional temperature management with the active full underbody forced warm-air system in the intervention group vs routine thermal management in the control group on bladder temperature at the different time points is shown in Figure 2. Intervention and control group had a similar bladder temperature at the end of $\mathrm{CPB}, \mathrm{T} 1\left(36.7^{\circ} \mathrm{C} \pm 0.3^{\circ} \mathrm{C}\right.$ vs $36.5^{\circ} \mathrm{C} \pm 0.2^{\circ} \mathrm{C}$, respectively;

Table 1. Baseline patient characteristics of control and intervention group.

\begin{tabular}{lccc}
\hline & $\begin{array}{c}\text { control group } \\
(\mathrm{n}=30)\end{array}$ & $\begin{array}{c}\text { intervention group } \\
(\mathrm{n}=30)\end{array}$ & P-value \\
\hline age (year) & $65 \pm 11$ & $70 \pm 8$ & $0.032^{*}$ \\
male/female (\%) & $26 / 4(86 / 14)$ & $22 / 8(73 / 27)$ & $\mathrm{ns}$ \\
weight $(\mathrm{kg})$ & $80 \pm 13$ & $80 \pm 12$ & $\mathrm{~ns}$ \\
height $(\mathrm{cm})$ & $175 \pm 8$ & $171 \pm 8$ & $\mathrm{~ns}$ \\
BMI $\left(\mathrm{kg} / \mathrm{m}^{2}\right)$ & $26 \pm 3$ & $27 \pm 4$ & $\mathrm{~ns}$ \\
no. of grafts & $4 \pm 1$ & $4 \pm 1$ & $\mathrm{~ns}$ \\
perfusion time (min) & $73 \pm 22$ & $77 \pm 19$ & $\mathrm{~ns}$ \\
cross clamp time (min) & $46 \pm 15$ & $52 \pm 15$ & $\mathrm{~ns}$ \\
\hline
\end{tabular}

Data are presented as mean $\pm \mathrm{SD}$ or in percentages; ${ }^{*}=$ significant if $\mathrm{P}<0.05$; $\mathrm{ns}=$ not significant.

\section{Core temperature at ICU arrival}

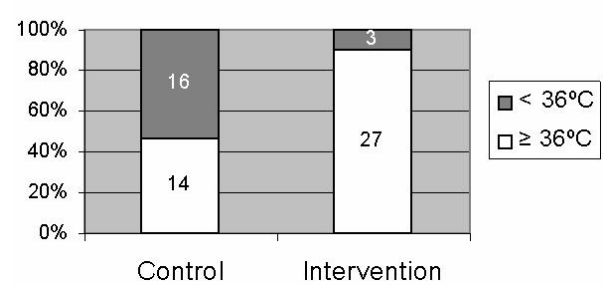

Figure 1. Core temperature upon ICU arrival between the control and the intervention group. Number of patients are shown. $\mathbf{P}<\mathbf{0 . 0 0 1}$.

NS). The core temperature in the intervention group was 
significantly higher compared to the control group at $\mathrm{T} 2$ 一sternal closure $\left(36.5^{\circ} \mathrm{C} \pm 0.3^{\circ} \mathrm{C}\right.$ vs $36.2^{\circ} \mathrm{C} \pm 0.3^{\circ} \mathrm{C} ; \mathrm{P}<$ $0.001), \mathrm{T} 3$-departure from $\mathrm{OR}\left(36.5^{\circ} \mathrm{C} \pm 0.3^{\circ} \mathrm{C}\right.$ vs $36.0^{\circ} \mathrm{C}$ $\left.\pm 0.3^{\circ} \mathrm{C} ; \mathrm{P}<0.001\right), \mathrm{T} 4-$ arrival in the $\mathrm{ICU}\left(36.2^{\circ} \mathrm{C} \pm\right.$ $0.3^{\circ} \mathrm{C}$ vs $\left.35.8^{\circ} \mathrm{C} \pm 0.4^{\circ} \mathrm{C} ; \mathrm{P}<0.001\right)$. The peripheral temperature in the intervention group was significantly higher as compared to the control group as shown in Figure 2. There was even a slight increase in the peripheral temperature from time point $\mathrm{T} 1$ to $\mathrm{T} 2$ in the intervention group.
The results of the secondary outcome measures are displayed in Table 2. While the time-interval, between the end of CPB and arrival in the ICU, was similar in both groups $((58 \pm 10)$ minutes vs $(55 \pm 14)$ minutes; $\mathrm{NS})$, the drop in temperature between the two groups was significantly less in the intervention group $\left(0.6^{\circ} \mathrm{C} \pm 0.3^{\circ} \mathrm{C}\right.$ vs $\left.0.4^{\circ} \mathrm{C} \pm 0.3^{\circ} \mathrm{C} ; \mathrm{P}=0.027\right)$.

Neither hemoglobin levels on arrival in the ICU (Intervention- vs control-group, $\mathrm{Hb}(5.7 \pm 0.6) \mathrm{mol} / \mathrm{L}$ vs

Core Temperature

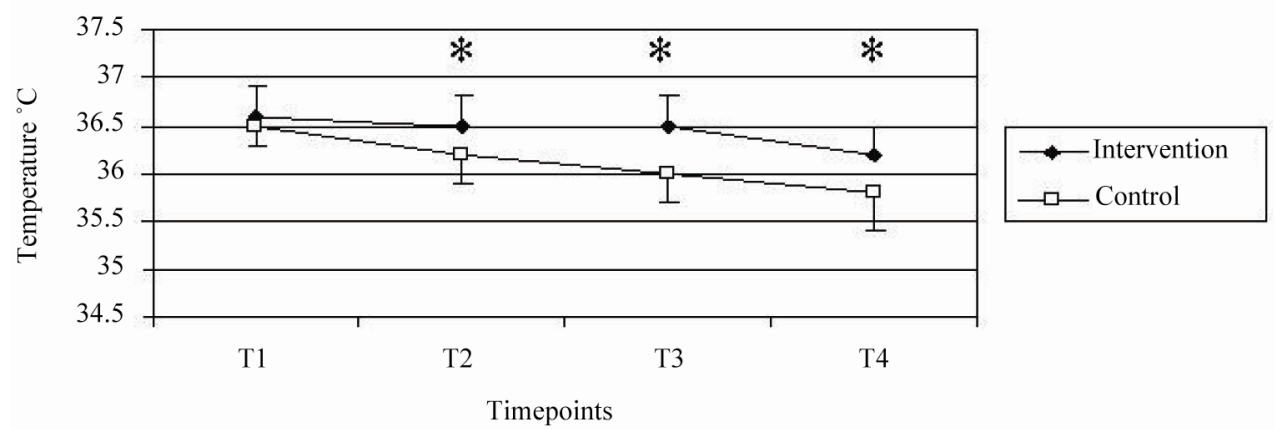

Peripheral Temperature

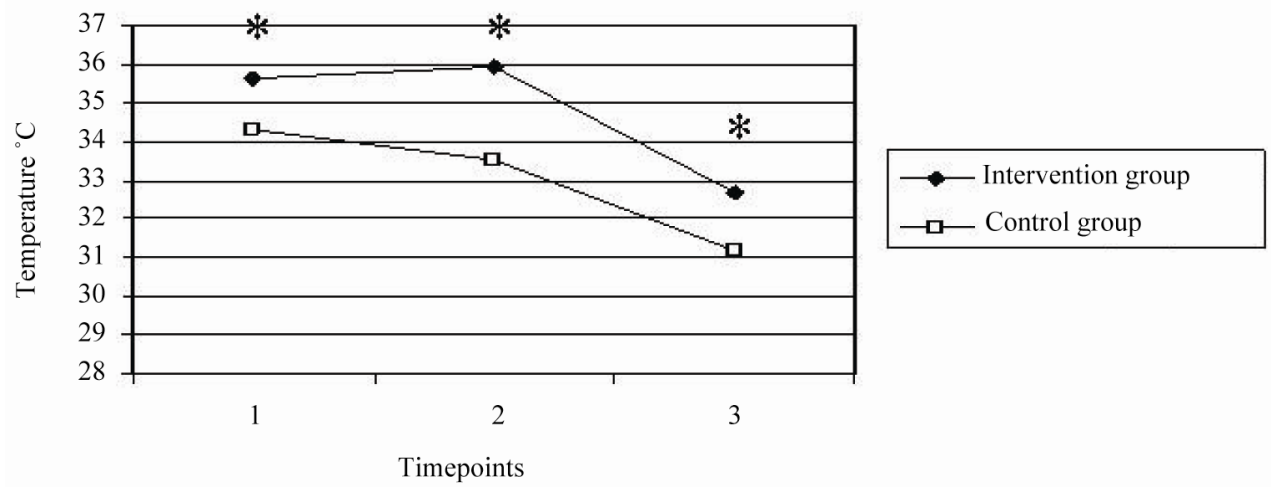

Figure 2. Effect of additional warmth management in the intervention group versus routine thermal management in the control group: on patients core temperature (top) during coronary artery bypass grafting at time points T1-T4 (with P-values < 0.05 at $\mathrm{T} 2-\mathrm{T} 4)$ and patients peripheral temperature during coronary artery bypass grafting at time points $\mathrm{T} 1, \mathrm{~T} 2$ and $\mathrm{T} 4$. (With P-values $<0.05$ at T1, T2 and T4).

Table 2. Main secondary outcome results.

\begin{tabular}{lccc}
\hline & control group $(\mathrm{n}=30)$ & intervention group $(\mathrm{n}=30)$ & P-value \\
\hline after-drop time $(\mathrm{min})$ & $55 \pm 14$ & $58 \pm 10$ & $\mathrm{~ns}$ \\
after-drop temp. $\left({ }^{\circ} \mathrm{C}\right)$ & $0.61 \pm 0.4$ & $0.42 \pm 0.3$ & $<0.027^{*}$ \\
no. patients arriving $\geq 36^{\circ} \mathrm{C}(\%)$ & $14(47 \%)$ & $27(90 \%)$ & $<0.001^{*}$ \\
time arrival ICU till $36^{\circ} \mathrm{C}(\mathrm{min})$ & $59 \pm 61$ & $8 \pm 25$ & $<0.001^{*}$ \\
temperature at extubation $\left({ }^{\circ} \mathrm{C}\right)$ & $37.9 \pm 0.5$ & $37.8 \pm 0.7$ & $\mathrm{~ns}$ \\
time at extubation $(\min )$ & $421 \pm 174$ & $368 \pm 149$ & $\mathrm{~ns}$ \\
\hline
\end{tabular}

Data are presented as mean $\pm \mathrm{SD}$ or in percentages; ${ }^{*}=$ significant if $\mathrm{P}<0.05 ; \mathrm{ns}=$ not significant. 
$(5.9 \pm 0.9) \mathrm{mol} / \mathrm{L})$, nor the total postoperative bloodloss was significantly different for both groups (Interventionvs control-group, $(812 \pm 314) \mathrm{mL}$ vs $(725 \pm 244) \mathrm{mL})$. Both groups received a comparable number of packed red blood cells.

\section{Discussion}

The use of an intra-operative underbody forced warm-air blanket significantly reduces the incidence of mild postoperative hypothermia in the early postoperative period in patients undergoing coronary artery bypass grafting with normothermic cardiopulmonary bypass.

The results of our study, however are not in concordance with the results from a study by Insler and Engelen $[11,12]$. Insler et al. investigating an underbody forced-air warming system during near-normothermic on-pump cardiac surgery $\left(35^{\circ} \mathrm{C}\right)$ concluded that the warming blanket significantly increased the temperature before $\mathrm{CPB}$ but not after CPB. They observed that patients undergoing near-normothermic thermal management did not become hypothermic in the first postoperative hours. They discussed that incomplete rewarming of peripheral tissues after CPB manifests as a large core-to-peripheral temperature gradient. A large core-to-peripheral temperature gradient results in a rapid temperature after-drop as heat redistributes from the core compartment to peripheral tissues as was observed in the study by Rajek et al. [13]. Maintaining a near-normothermic CPB-temperature decreases the core-to-peripheral tissue gradient and in this manner decreases the after-drop in temperature. Since the patients in the control-group in their study had a very small after-drop in temperature, that was not significantly different from the intervention-group, they concluded that the warming-device did not actively prevent the after-drop in temperature in the postoperative period.

In our study, the peripheral temperature at separation from CPB was significantly higher in the intervention group and there was an initial slight increase in the peripheral temperature (Figure 2) in this group. The coreto-peripheral temperature gradient at separation from the CPB was significantly smaller in the intervention group $\left(1.1^{\circ} \mathrm{C}\right.$ versus $\left.2.2^{\circ} \mathrm{C}\right)$. From these observations we concluded that the underbody forced warm-air blanket did contribute to the maintenance of the patients core and peripheral temperature after separation from the CPB.

Engelen et al. investigating an underbody forced-air warming system during near-normothermic $\left(35^{\circ} \mathrm{C}-38^{\circ} \mathrm{C}\right)$ on-pump cardiac surgery concluded that during the postCPB period the decrease in core temperature on arrival in the ICU $\left(35^{\circ} \mathrm{C}\right)$ still mandated rescue warming of the patients [12]. They concluded that the patients temperature in the post-CPB period is largely determined by the patients temperature at termination of $\mathrm{CPB}$

We agree with the authors that the level of the core temperature at separation from CPB is of influence on the patients core temperature in the post-CPB period. Normothermic or near-normothermic CPB means maintaining a core temperature below $37^{\circ} \mathrm{C}$, the patients' normal core temperature. The smaller the difference in absolute core temperature after separation from the $\mathrm{CPB}$ and the normal homeostatic strive temperature of the body, the less the patients temperature regulation mechanisms have to work in order to increase the bodies core temperature and the less time it takes to reach $37^{\circ} \mathrm{C}$.

Several reports have shown that even mild perioperative hypothermia causes evident postoperative thermal discomfort $[14,15]$. Patients have consistently indicated that feeling cold postoperatively was the worst part of their hospitalization, sometimes rating it even worse than surgical pain. Given the appropriate efforts to treat surgical pain, it would seem appropriate to prevent and treat thermal discomfort $[3,16]$. It is considered standard care in this clinical setting to sedate patients who experience thermal discomfort until they are rewarmed.

All secondary results did not differ significantly between groups. However, this study was only powered for the primary outcome variable, and a larger patient sample is needed to investigate the effect of warmth management on parameters of post-operative management. Postoperative blood loss for instance, as a marker of hypothermic coagulopathy, was similar in both groups. Evidently, much larger patient groups are necessary to study an effect of mild hypothermia on coagulation and blood loss.

The relative contribution of warming devices in maintaining normothermia increases with age as intrinsic thermoregulatory control decreases with age $[17,18]$. In the present study, the patients in the Intervention group were significantly older than in the control group. This could have negatively affected the speed of rewarming in the Intervention group. This suggests that the beneficial effect of the mattress on thermoregulation in the Intervention group could have been even more favourable as compared to the control group in this study. Since most identified hypothermia-induced complications are established intraoperatively, patients should be warmed during surgery rather than allowed to cool down and then be "rescued" and warmed postoperatively [3,19]. This study shows that additional warmth management with a full underbody forced warm-air system, applied in the operating room to patients undergoing normothermic coronary artery bypass surgery, prevents mild hypothermia and makes the use of active rewarming devices in the early postoperative phase unnecessary. This evidently contributes to the cost-effectiveness of using active heating devices in the perioperative period. 
In summary, normothermic $\mathrm{CPB}$ results in a higher core temperature (around $36^{\circ} \mathrm{C}$ ) and a small peripheralto-core-gradient at separation from CPB. Maintaining a high peripheral temperature and a small peripheral-tocore-gradient definitely contribute to the prevention of the after-drop in core temperature. The inevitable decrease of the peripheral temperature, increase of the peripheral-to-core-gradient, and therefore drop in core temperature in our study is diminished by the use of the underbody forced warm-air blanket.

\section{REFERENCES}

[1] D. I. Sessler, "Temperature Monitoring and Perioperative Thermoregulation," Anesthesiology, Vol. 109, No. 2, 2008, pp. 318-338. doi:10.1097/ALN.0b013e31817f6d76

[2] D. J. Buggy and A. W. Crossley, "Thermoregulation, Mild Perioperative Hypothermia and Postanaesthetic Shivering," British Journal of Anaesthesia, Vol. 84, No. 5, 2000, pp. 615-628. doi:10.1093/bja/84.5.615

[3] D. I. Sessler, "Complications and Treatment of Mild Hypothermia," Anesthesiology, Vol. 95, No. 2, 2001, pp. 531543.

[4] A. W. Crossley, "Peri-Operative Shivering," Anaesthesia, Vol. 47, No. 3, 1992, pp. 193-195. doi:10.1111/j.1365-2044.1992.tb02114.x

[5] S. Rajagopalan, E. Mascha, J. Na and D. I. Sessler, "The Effects of Mild Perioperative Hypothermia on Blood Loss and Transfusion Requirement," Anesthesiology, Vol. 108, No. 1, 2008, pp. 71-77.

[6] C. K. Hofer, M. Worn, R. Tavakoli, L. Sander, M. Maloigne, R. Klaghofer and A. Zollinger, "Influence of Body Core Temperature on Blood Loss and Transfusion Requirements during Off-Pump Coronary Artery Bypass Grafting: A Comparison of 3 Warming Systems," Journal of Thoracic and Cardiovascular Surgery, Vol. 129, No. 4, 2005, pp. 838-843.

[7] A. Kurz, D. I. Sessler and R. Lenhardt, "Perioperative Normothermia to Reduce the Incidence of Surgical-Wound Infection and Shorten Hospitalization," New England Journal of Medicine, Vol. 334, No. 19, 1996, pp. 1209-1215.

[8] S. M. Frank, L. A. Fleisher, M. J. Breslow, M. S. Higgins, K. F. Olson, S. Kelly and C. Beattie, "Perioperative Maintenance of Normothermia Reduces the Incidence of Morbid Cardiac Events. A Randomized Clinical Trial," Journal of the American Medical Association, Vol. 277, No. 14, 1997, pp. 1127-1134.

[9] R. Lenhardt, E. Marker, V. Goll, H. Tschernich, A. Kurz, D. I. Sessler, et al., "Mild Intraoperative Hypothermia Prolongs Postanesthetic Recovery," Anesthesiology, Vol.
87, No. 6, 1997, pp. 1318-1323.

[10] J. Heijmans, G. V. Mastrigt, J. Maessen and P. Roekaerts, "Shortening ICU Stay after Coronary Artery Surgery," In: J. H. Heijmans, Eds., Introducing Short-Stay Intensive Care after Coronary Artery Surgery, Datawyse/Universitaire Pers, Maastricht, 2007, pp. 119-133.

[11] S. R. Insler, M. H. Bakri, F. Nageeb, E. Mascha, T. Mihaljevic and D. I. Sessler, "An Evaluation of a Full-Access Underbody Forced-Air Warming System during NearNormothermic, On-Pump Cardiac Surgery," Anesthesia \& Analgesia, Vol. 106, No. 3, 2008, pp. 746-750.

[12] S. Engelen, D. Himpe, S. Borms, J. Berghmans, P. Van Cauwelaert, J. E. Dalton and D. I. Sessler, "An Evaluation of Underbody Forced-Air and Resistive Heating during Hypothermic, On-Pump Cardiac Surgery," Anaesthesia, Vol. 66, No. 2, 2011, pp. 104-110.

[13] A. Rajek, R. Lenhardt, D. I. Sessler, A. Kurz, G. Laufer, R. Christensen, T. Matsukawa and M. Hiesmayr, "Tissue Heat Content and Distribution during and after Cardiopulmonary Bypass at $31^{\circ} \mathrm{C}$ and $27^{\circ} \mathrm{C}$," Anesthesiology, Vol. 88, No. 6, 1998, pp. 1511-1518.

[14] D. I. Sessler, E. H. Rubinstein and A. Moayeri, "Physiologic Responses to Mild Perianesthetic Hypothermia in Humans," Anesthesiology, Vol. 75, No. 4, 1991, pp. 594 610.

[15] A. Kurz, D. I. Sessler, E. Narzt, A. Behar, R. Lenhardt, G. Huemer and F. Lachner, "Postoperative Hemodynamic and Thermoregulatory Consequences of Intraoperative Core Hypothermia," Journal of Clinical Anesthesia, Vol. 7, No. 5, 1995, pp. 359-366. doi:10.1016/0952-8180(95)00028-G

[16] S. M. Frank, M. S. Higgins, M. J. Breslow, L. A. Fleisher, R. B. Gorman, J. V. Sitzman, et al., "The Catecholamine, Cortisol, and Hemodynamic Responses to Mild Perioperative Hypothermia, a Randomized Clinical Trial," Anesthesiology, Vol. 82, No. 1, 1995, pp. 83-93.

[17] M. S. Vaughan, R. W. Vaughan and R. C. Cork, "Postoperative Hypothermia in Adults: Relationship of Age, Anesthesia, and Shivering to Rewarming," Anesthesia \& Analgesia, Vol. 60, No. 10, 1981, pp. 746-751.

[18] A. Kurz, O. Plattner, D. I. Sessler, G. Huemer, G. Redl, and F. Lackner, "The Threshold for Thermoregulatory Vasoconstriction during Nitrous Oxide/Isoflurance Anesthesia Is Lower in Elderly than in Young Patients," Anesthesiology, Vol. 79, No. 3, 1993, pp. 465-469.

[19] D. Galante, "Intraoperative Hypothermia. Relation between General and Regional Anesthesia, Upper- and Lower-Body Warming: What Strategies in Pediatric Anesthesia?" Pediatric Anesthesia, Vol 17, No. 9, 2007, pp. 821-823. doi:10.1111/j.1460-9592.2007.02248.x 